\title{
A General Strain Theory of Intimate Partner Homicide
}

Li Eriksson $^{\mathrm{a}}$ (corresponding author) and Paul Mazerolle ${ }^{\mathrm{b}}$

${ }^{a}$ Key Centre for Ethics, Law, Justice and Governance

176 Messines Ridge Road

Mt Gravatt Campus, Griffith University

QLD 4122 Australia

Email: 1.eriksson@griffith.edu.au

Phone: +61-7-37351164

Fax: +61-7-37356985

${ }^{\mathrm{b}}$ PVC (Arts, Education, Law)

176 Messines Ridge Road

Mt Gravatt Campus, Griffith University

QLD 4122 Australia

Email: p.mazerolle@griffith.edu.au

Phone: +61-7-37355710

Fax: +61-7-37355717 


\begin{abstract}
Men and women who kill an intimate partner experience qualitatively different situations and emotions in the months and weeks preceding the homicide event. Theoretical explanations of intimate partner homicide are either gender-specific or gender-neutral, and, as such, fail to take these gender differences into account. This article extends current theory by presenting a general strain theory of intimate partner homicide. General strain theory suggests that men and women who kill an intimate partner experience different types of strain and emotions, and that homicide occurs in response to these experiences. This application not only affords gender-sensitivity, but also incorporates negative emotions (often neglected by other theory-building), explains coping mechanisms, and combines proximal and distal etiological factors.
\end{abstract}

\title{
Keywords
}

general strain theory; strain; intimate partner homicide; intimate partner violence; emotions; criminological theory 


\section{Introduction}

Intimate partner homicide (IPH) is gendered. Men and women who kill a current or former intimate partner experience distinctly different situations and emotions in the months and weeks preceding the homicide event. Men who kill their partners report experiences of losing control, suspecting infidelity, involuntary separation, jealousy, and rage (Daly \& Wilson, 1988; Johnson \& Hotton, 2003; Polk, 1994; Wallace, 1986). In contrast, women who kill their partners report feelings of fear and desperation resulting from exposure to domestic violence and social isolation (Mills, 1985; Stark, 2007). These gender differences pose great challenges to theoretical explanations, which need to take these qualitatively different situational and emotional experiences into account.

Criminological theorizing has received criticism for its exclusive focus on the explanation of male behavior (Daly \& Chesney-Lind, 1988). Given that the majority of IPH perpetrators are male, it is perhaps not surprising that theories examining IPH have predominantly sought to explain male perpetration patterns (e.g. Daly \& Wilson, 1988; Taylor \& Jasinski, 2011), although some theorizing, particularly self-help based, specifically examines female perpetrators (Black, 1983; Peterson, 1999). Such gender-specific theory development, although potentially powerful in its explanations of the phenomenon as gendered per se, might miss important commonalities and diversities in IPH perpetration patterns - commonalities as well as dissimilarities that can have implications not only for further theory building, but for the formation of policy and intervention. However, general theories applied to IPH (e.g., Swatt \& He, 2006; Wolfgang, 1957) tend to neglect gendersensitivities.

Although homicide is often viewed as an extension of partner violence, research suggests important differences between lethal and non-lethal acts, such as male IPH perpetrators displaying more possessiveness and being less likely to have consumed alcohol 
at the time of the offence (Dobash, Dobash, Cavanagh, \& Medina-Ariza, 2007). These findings warrant the need to theoretically and empirically examine IPH as a separate phenomenon. It is argued in this article that general strain theory (GST) extends current IPH theories in a number of ways: it provides a unique gender-sensitive framework, accounts for the role of negative emotions, explains why some, but not all, individuals kill their intimate partners, and incorporates a wide range of correlates identified in the literature into an efficient yet comprehensive explanation of IPH.

The article is divided into four sections. First, we examine the empirical literature identifying correlates of IPH perpetration, followed by a review of current theoretical approaches. We then present a GST explanation of IPH, describing how and why GST improves upon existing theories and detailing a number of research hypotheses. Finally, we also include a comprehensive agenda for future research on IPH, exploring research designs and data collection tools that allow for direct empirical testing of our research hypotheses.

\section{Characteristics of Intimate Partner Homicide}

IPH is best understood within the gendered context in which it occurs. Males are overrepresented as perpetrators of IPH, although when women kill they are more likely to kill an intimate partner than someone else (Dearden \& Jones, 2008; Wilson \& Daly, 1992). Although certain socio-demographic characteristics, such as offender-victim age disparity (Daly \& Wilson, 1988), ethnic background (Trainor \& Mihorean, 2001) and social and economic disadvantage (Campbell et al., 2003) share commonalities across gender, other factors, such as perpetrator and relationship characteristics and situational contexts, differ extensively between the genders. Interviews with male IPH perpetrators reveal controlling attitudes, including jealousy and entitlement, especially in reaction to relationship breakdown (Dobash et al., 2007; Wallace, 1986; Wilson \& Daly, 1993b). Separation is one of the most prominent predictors of IPH victimization among women, with risks decreasing with the 
length of separation (Johnson \& Hotton, 2003; Wallace, 1986). Often the lethal act is preceded by long-term non-lethal violence directed both towards the female partner and other family members, including children (Browne, 1987; Campbell et al., 2003; Stout, 1993). In contrast, research suggests that women kill in self-defense and report experiencing anxiety and fear (Browne, 1987; Walker, 1989). If women's IPH perpetration is self-defensive, this would explain why men are more at risk of IPH victimization while in intact relationships (Johnson \& Hotton, 2003).

\section{Existing Theoretical Explanations of Intimate Partner Homicide}

While a range of theories have been applied to non-lethal partner violence, limited theorizing has been extended to IPH perpetration. Given that only a small proportion of nonlethal violence perpetrators commit homicide and that research suggests important differences between lethal and non-lethal violence (Dobash et al., 2007), the focus here is exclusively on the most prominent theories explaining lethal violence perpetration. Some of these theories place emphasis on macro-level processes, while others direct attention to micro-level processes. However, the majority of these theories are gender-specific. For example, according to evolutionary theories, lethal and non-lethal partner acts of violence are adaptive responses by males confronted with perceived threats to their relationship (Daly \& Wilson, 1988; Duntley \& Buss, 2008). Fearing sexual competition and infidelity, including cuckolding (the rearing of a child to whom one is not the father), men experience sexual jealousy, which is the psychological link between the perceived threat of sexual infidelity and the violent act (Wilson \& Daly, 1993a).

Similarly, feminist theories highlight the role of male control and entitlement. As the most commonly applied theories of IPH, radical and socialist feminist explanations of violence provide valuable insights into how individual, familial, and societal endorsements of patriarchal values are associated with men's lethal and non-lethal partner violence (Daly \& 
Chesney-Lind, 1988; Dobash \& Dobash, 1979; Klein, 1981). With increased gender equality we would expect either reduced rates of male-perpetrated IPH resulting from increased access to support services for battered women (the ameliorative hypothesis) or higher rates of maleperpetrated IPH as a means of controlling 'liberated' women (the backlash hypothesis) (Dugan, Rosenfeld, \& Nagin, 2003).

Directing attention to female perpetration patterns, social control perspectives view female partner violence perpetration as extreme self-help behavior (Black, 1983; Browne, 1987; Peterson, 1999). In particular, Peterson (1999) emphasizes experiences of social isolation, fear, and limited access to legal forms of social control as important in understanding of female-perpetrated IPH. Other theories take a more gender-neutral approach. For example, according to symbolic interactionist perspectives, people engage in violence in order to gain compliance, redress grievances or defend their identity and it is through the unfolding of the event that victim-offender roles become clear (Felson \& Tedeschi, 1993; Wolfgang, 1957). Applied to IPH, symbolic interactionism highlights the importance of taking the situational and relational context of violent altercations into account (Swatt \& He, 2006).

\section{Gaps and Limitations of Existing Theories}

As described above, the theoretical explanatory landscape applied to IPH is both diverse and compelling. However, at the same time, surveying the theoretical landscape on this issue illustrates numerous explanatory gaps, as well as opportunities for further theoretical development and refinement. Importantly, while some theories provide generalist approaches, many provide only partial explanatory perspectives informed by gender. As gender is a distinguishing feature of IPH, any explanatory framework needs to allow for gender-sensitive analyses that can explain not only why men are overrepresented as perpetrators, but also why some women do engage in this type of violent behavior. 
Furthermore, although it has been argued that all offenses have an instrumental quality to them (see Felson \& Tedeschi, 1993) violent acts between individuals in close relationships contain high levels of emotional and expressive characteristics, particularly among male but also among female perpetrators (Browne, 1987; Polk, 1994; Walker, 1989). Current theories do not adequately capture the role of emotions in homicide perpetration. Although expressive features of IPH are explored in evolutionary theories, it does not extend beyond the experience of jealousy. Further, the focus within feminist theories is more on emotive-facilitative traits, such as hypersensitivity to perceived threats, rather than emotional states. Other theorizing, including symbolic interactionism, does not specifically examine emotions. Recent years have seen calls for greater understanding of emotions in theoretical applications of criminal behavior and criminal justice responses (e.g., Sherman, 2003). Given the central role emotions play in IPH perpetration there is a need for theories to specifically consider and account for how and why experiences of emotions are associated with homicide perpetration.

Moreover, while non-lethal partner violence occurs frequently across the community, with international victimization surveys estimating lifetime prevalence rates of between 20 and $70 \%$ (Garcia-Moreno, Jansen, Ellsberg, Heise, \& Watts, 2006; Tjaden \& Thoennes, 2000) only a small proportion of these incidents result in homicide, indicating that IPH is a clear behavioral exception rather than the norm. The question of why most people do not commit crime is recognized in the field of criminology more broadly (e.g., Hirschi, 1969), however current theoretical explanations of IPH offer limited advice on why, for example, the majority of males with possessive dispositions who experience relationship separation ultimately do not kill their partner, or why not all situations in which an individual experiences the need to redress grievances result in homicide. Thus, a theoretical explanation of IPH must be able to explain why some, but not all, individuals kill their partners. 


\section{What Does General Strain Theory Offer?}

By putting gender at the forefront of theoretical and empirical enquiry, GST has the potential to account for differences in the experiences of male and female IPH perpetrators. GST further treats emotional reactions as important mediators between adverse experiences and criminal involvement and recognizes that these emotions differ for men and women. Given the centrality of emotions in partner homicides, GST, thus, has the potential to provide a valuable contribution to the theoretical landscape of IPH. GST further incorporates individual and gender differences in the availability of resources and coping strategies. This helps explain why some individuals experiencing difficult situations cope better than others, allowing for GST to account for both perpetration and abstention of homicidal acts. Importantly, the theoretical statements generated by GST allow for direct empirical testing, permitting the theory to be assessed, refined, elaborated, or rejected. This is a necessary feature of social theories, and given the abstract nature of some extant theories of IPH there have been limited attempts to empirically assess the main ideas informing the theory. In short, valid theories require empirical assessment to assess claims and we are further impoverished when current theories are structured in ways that work against stated assertions which can be subjected to empirical scrutiny.

\section{A Brief Overview of General Strain Theory}

According to GST, experiences of strain increase the likelihood of criminal behavior (Agnew, 1992). There are three main categories of strain: experiencing aversive events, losing something positively valued and being prevented from achieving one's goals. GST distinguishes between objective strain, which refers to events or conditions that are considered adverse by most individuals in a given group, and the subjective evaluation of a given strain (Agnew, 2001). For example, relationship separation may be experienced as particularly aversive to some, while others may consider this as a relatively constructive 
event. Thus, it is important to estimate individual assessments of situations in order to understand the degree to which these events are perceived as negative or stressful to that particular individual. Theoretically, subjective strain should have a stronger correlation with criminal behavior than objective strain. Similarly, strain can also be anticipated or experienced vicariously through others, although direct experiences of strain are considered most relevant to criminal outcomes (Agnew, 2002).

The link between strain and criminal behavior operates partly through negative emotions (Agnew, 1992). Experiencing strain has been linked to a variety of negative emotions, including anger, resentment, anxiety, and depression (Brezina, 1996). Different types of strain may lead to different emotional reactions, in the same way that certain emotions may be more related to particular criminal outcomes. For example, research shows anger to be more strongly linked to interpersonal aggression than property crime (Piquero \& Sealock, 2000). Crime is, thus, an illegitimate means of coping with experiences of strain and negative emotions, allowing the individual to escape or reduce the amount of strain and negative emotions or take revenge against the individual or situation that caused the strain (Agnew, 1992).

However, not all strains are equally likely to result in crime. Certain characteristics of strain are particularly relevant in explaining criminal behavior. One such characteristic is the magnitude, which refers to the quantity or severity of the strain (degree), how long and how often the strain is experienced (duration), the amount of time passed since the strain was inflicted (recency) and the extent to which the strain threatens the core goals, needs, values, activities, and/or identities of the individual experiencing the strain (centrality) (Agnew, 2001). Not only may strain high in magnitude generate more feelings of anger, they may also reduce an individual's ability to legitimately cope with the strain. Furthermore, strains that are experienced as unjust are more likely to be associated with feelings of anger, thereby 
increasing the likelihood of crime. Other characteristics affecting the likelihood of criminal coping include strains associated with low social control and those associated with pressures or incentives for turning to crime (Agnew, 2001).

While most individuals are exposed to strain and negative emotions at some point in their life, not everyone turns to crime. According to GST, certain factors condition and affect individual coping strategies. Individuals exhibiting low self-efficacy are more likely to turn to crime due to limited or inadequate beliefs in their own abilities to cope legally with adverse events (Agnew, 2006). Negative emotionality and low constraint increase the likelihood of criminal coping in a number of ways, including impulsive behavior in reaction to strain, inadequate social skills, a general lack of concern for others, and a tendency to attribute ones adversities to the actions of others (Agnew, Brezina, Wright, \& Cullen, 2002). Similarly, individuals who hold accepting attitudes toward criminal activity are more likely to turn to criminal coping than individuals who disapprove of criminal behavior (Agnew, 1992). These attitudes might also be affected by delinquent peer group involvement where delinquent behavior is modeled and reinforced. In contrast, access to conventional social support and legal resources provide individuals with the ability to better cope with stressful events through legitimate means (Agnew, 1992). Furthermore, individuals who are directly controlled by, or experience a bond with, family and society in general are less likely to engage in crime since they have more to lose than someone without this form of social control (Agnew, 2006).

\subsection{The Role of Gender}

GST has the potential to explain both male and female criminal behavior by focusing on how gender conditions the processes linking strain to criminal behavior (Broidy \& Agnew, 1997). This approach allows GST to explain why men are more likely to engage in criminal behavior compared to women. First, while men and women are exposed to similar levels of 
strain, the types of strains and subjective experiences of these strains are qualitatively different. For example, while females are generally more concerned with interpersonal relationships and procedural justice, males are more likely to value financial status and fair outcomes (Broidy \& Agnew, 1997; Conger, Lorenz, Elder, Simons, \& Ge, 1993). It is, therefore, important to identify distinct gender-specific strains. Second, while the mediating process of emotions linking strain to crime remains the same for both genders, the types of emotions experienced differ. Men and women are equally as likely to respond to strain with anger; however, female anger is more often accompanied by other emotions such as depression and anxiety (Broidy \& Agnew, 1997; Thomas, 1993). In contrast, male anger is more often characterized by feelings of moral outrage. A reason for these gender differences is that males tend to externalize their blame onto others while females internalize blame and thus engage in more inner-directed forms of deviance (Broidy \& Agnew, 1997; Thomas, 1993). Third, men and women also differ in their exposure to, and experience with, conditioning factors that make crime more or less likely to occur (Broidy \& Agnew, 1997). For example, research shows that men are more likely to associate with delinquent peers (Piquero, Gover, MacDonald, \& Piquero, 2005).

GST further explains why some women engage in crime, by identifying strains of particular relevance to women (Broidy \& Agnew, 1997). One example of this is victimization. Women are exposed to aversive stimuli within the household, such as physical, sexual and emotional abuse, to a much greater extent than men. As women are particularly concerned with interpersonal ties, the failure to achieve a happy and healthy intimate relationship due to abuse may be perceived as highly stressful. In terms of conditioning factors, Broidy and Agnew (1997) note that women who engage in criminal behavior are more likely to hold criminal beliefs, associate with criminal peers, experience low social control, and have more opportunities to engage in crime. They further note that perceived 
unavailability of non-criminal coping strategies may lead women to commit crime, for example, in the case of abusive relationships.

\section{A General Strain Theory of Intimate Partner Homicide}

Previous research has identified the validity of using GST as a theoretical framework for explaining non-lethal partner violence (Anderson \& Lo, 2011; Katz, 2000). Moreover, research recognizes the applicability of examining strain in the context of IPH, particularly as they relate to backlash effects of increased accessibility to domestic violence resources (see Dugan et al., 2003). Building on the theoretical work of Broidy and Agnew (1997) and the IPH literature this article identifies a number of gender-specific strains, negative emotions and conditioning factors, as presented in Figure 1. This model represents a new and gendersensitive framework for understanding empirically important correlates of IPH.

\section{Figure 1 about here}

As per Figure 1, this framework identifies that separate strains, negative emotions, and conditioning factors are relevant for male and female IPH perpetration. While the differences between men and women are sometimes a matter of degree, rather than kind (see Broidy \& Agnew, 1997), this model recognizes that the most salient variables related to IPH perpetration do differ in important ways between men and women. Therefore, it is necessary to identify the unique constellation of factors that contribute to male and female IPH perpetration. For instance, while loss of control, relationship separation and perceived infidelity have been linked to the men who kill their partners, the majority of female perpetrators experience distinctly different types of strain, such as restricted freedom and exposure to abuse. Similarly, negative emotions associated with male experiences of strain are distinctly different to female experiences. Moreover, the model identifies gender differentiation in terms of disposition to, and constraints against, IPH perpetration. A detailed 
description of the model is provided in the following sections, providing analyses of the existing theoretical and empirical literature and a rationale for a GST application of IPH.

\subsection{Male Perpetrators of Intimate Partner Homicide}

\subsubsection{Sources of strain}

The use of violence, or threat thereof, as a means of controlling others' behavior and thereby generating compliance is a prominent theme in much of the literature on lethal and non-lethal male partner violence (Daly \& Wilson, 1988; Dobash \& Dobash, 1979; Johnson, 1995; Klein, 1981). For example, control as a source of strain is a central hypothesis in research on the backlash effect of domestic violence resources on male-perpetrated IPH (Dugan et al., 2003). In this way, male perpetrators who have a need for control may respond with lethal violence to the perceived emancipation of their partners. Given the importance of control issues in IPH research, it is expected that men's failure to achieve control in a relationship functions as a source of strain in that they are prevented from achieving a positively valued goal. Similarly, the failure to maintain control has been identified in research on violence in reaction to perceived questioning of male authority (Dobash \& Dobash, 1979) and relationship separation (Johnson \& Hotton, 2003). This sense of not maintaining control has long been recognized as an important variable in explaining partner violence perpetrated by men (Gondolf, 1985; Polk, 1994). Using GST terminology, it is expected that males who initially perceive themselves as being in control of their partner and subsequently experience a loss of this control experience a removal of positively valued stimuli. In this context, threatened loss of control operates as anticipated strain. The magnitude of this type of strain would be particularly intensified for men whose sense of entitlement forms a core part of their identity (affecting the centrality characteristic of strain).

Relationship separation may be the catalyst strain for experiences of losing control. In fact, relationship separation is one of the most prominent risk factors for IPH victimization 
among women (Johnson \& Hotton, 2003; Wallace, 1986; Wilson \& Daly, 1993b). Research shows that experiences of separation are more common among lethal compared to non-lethal intimate partner violence perpetrators (Dobash et al., 2007). Recently, strain theorists have also begun exploring the impact separation has on criminal behavior, with research showing subjective negative ratings of relationship break-downs to be related to criminal involvement in youth (Froggio \& Agnew, 2007). Given the emphasis afforded this issue, particularly in IPH research, it is expected that relationship separation acts to remove positively valued stimuli. As most homicides occur within the first few months after separation (Wallace, 1986), it is expected that event recency will have an important impact on subjective evaluations of strain magnitude. Furthermore, it is expected that the threat of separation (see Wilson \& Daly, 1993b) acts as anticipated strain.

Evolutionary psychologists stress the importance of examining effects of perceived infidelity (Wilson \& Daly, 1993a). Comparing the reasons for relationship separation between female IPH victims and comparison groups of abused women, Campbell et al. (2003) found an increased risk of homicide victimization for women who had left their partner for another relationship. This, in particular, appeared to mediate the relationship between controlling behavior and IPH. It is thus anticipated that actual, and perhaps more importantly suspected (see Browne, 1987), exposure to infidelity acts as the presentation of negatively valued stimuli for male IPH perpetrators.

Further related to relationship separation are disputes over child custody, which has been shown to precipitate some IPH cases (Wallace, 1986). In research on child murder, Johnson (2005) specifically notes the escalation of male violence and stalking after separation, including threats to kill or harm the partner and/or the children. It has further been suggested that harming the children may be a means of retaliating against the partner (McCloskey, 2001) or preventing the partner from leaving the relationship (Stahly, 2000). 
Although limited research has examined the role of child custody disputes on IPH, it is expected that males who lose access to their children (including anticipated loss) through relationship separation or other means experience removal of positively valued stimuli.

Violent men who subsequently kill their partners have often been subject to prior legal interventions. Research shows the presence of previous domestic violence protection orders in over one-quarter of IPH involving a female victim (Websdale, 1999). While some IPH research finds a protective effect of arrest (Campbell et al., 2003), other research suggests it might be counterproductive (Gauthier \& Bankston, 2004). In line with 'backlash' arguments, it may be that legal interventions create further stress and conflict within the relationship and thus may put women in more danger (see Dugan et al., 2003). It is, therefore, expected that protection orders and arrests are experienced as presentations of negatively valued strain, but also as removal of positively valued stimuli due to imposed restricted access to the female partner. Although GST states that strains associated with high social control should correlate negatively with crime (Agnew, 2006), men who believe their violence is justified may experience being issued a protection order as unjust, a characteristic of strain that serves to lower social control and increase the amount of anger experienced (Agnew, 2001). This is supported by research showing that perceptions of procedural justice play a role in decreasing intimate partner violence recidivism rates (Paternoster, Brame, Bachman, \& Sherman, 1997).

\subsubsection{Negative emotional reactions to strain}

According to GST, strain operates through negative emotions, and the IPH literature is filled with accounts of anger, rage and sexual jealousy. Coroners' records of IPH cases show presence of morbid jealousy, abandonment-rage, and intense anger, to the extent that some perpetrators report a sense of relief after the incident (Polk, 1994). In interviews, IPH perpetrators report higher levels of possessiveness and jealousy than perpetrators of non- 
lethal violence (Dobash et al., 2007). Similarly, female victims of attempted IPH report that their partner displayed extreme levels of jealousy prior to the incident (Nicolaidis et al., 2003). GST research also finds anger and rage to be emotional reactions to strain among males, and suggests that although levels of anger are similar across gender, this is more likely to result in violent acts among men (Mazerolle, Piquero, \& Capowich, 2003; Piquero \& Sealock, 2004). From the literature, it is thus expected that anger, rage and jealousy, are key emotions that mediate the relationship between experiences of strain and IPH perpetration. The perpetration of IPH may thus be a means of dealing with the intense negative emotions experienced in reaction to strain such as losing control, going through a separation, suspecting infidelity or receiving a protection order.

\subsubsection{Factors conditioning the effect of strain on intimate partner homicide}

Of the conditioning variables identified by GST to increase the likelihood of crime, personality traits, beliefs favorable to crime and associating with criminal peers are particularly relevant in explaining male IPH perpetration. ${ }^{1}$ In terms of personality traits, GST research suggests that negative emotionality (also known as trait anger) and low constraint (also known as impulsivity) condition the effect of strain on criminal behavior (Agnew et al., 2002). Although conceptualizations of negative emotionality have been virtually absent in the partner violence literature, Moffitt, Krueger, Caspi, and Fagan (2000) note that feminist and evolutionary theories discuss personality characteristics of male perpetrators of partner violence in terminology similar to negative emotionality. Moffitt et al. argue that hypersensitivity to perceived threats and expected rejection are important characteristics of negative emotionality in terms of explaining violence. Their findings further suggest that

\footnotetext{
${ }^{1}$ GST further identifies a number of conditioning variables that are expected to increase the likelihood of criminal coping, including poor problem-solving and social skills, low self-efficacy and low social support (Agnew, 2006). As these have not been identified in the homicide literature as significant correlates of male IPH perpetration they are not discussed at length here. However, this should not exclude them from future theoretical and empirical scrutiny.
} 
while individuals who 'specialize' in partner violence do not display low constraint, individuals who are violent towards others as well as their partners do display impulsive personality characteristics. Similarly, examining individuals convicted of lethal and nonlethal partner violence, Grann and Wedin (2002) found that higher levels of impulsivity significantly increased recidivism rates. As individuals with negative emotionality and low constraint are less likely to be concerned with the cost of crime and more likely to experience strains as unjust and high in magnitude, it is expected that these individuals are more likely to react to strain with lethal violence.

In terms of attitudes toward partner violence, Straus (1980) found that individuals who approved of slapping a spouse were over five times more likely to engage in partner violence when experiencing high levels of stress than individuals who disapproved of this form of violence. Similarly, research by Holtzworth-Munroe, Meehan, Herron, Rehman and Stuart (2000) suggests that males reporting high levels of marital violence hold more accepting attitudes towards partner violence than males reporting lower levels or no involvement in marital violence. This reinforcement may originate from peers, with research suggesting that associating with peers who approve of or engage in intimate partner violence is related to perpetration of such acts (DeKeseredy \& Schwartz, 1998). GST states that holding beliefs favorable to crime and associating with criminal peers are factors that lower an individual's perceived cost of crime, reduce their access to legal coping strategies and affect the way in which an individual perceives strain, thereby increasing the likelihood of criminal coping (Agnew, 2006). It is, therefore, expected that men holding condoning attitudes toward partner violence or associating with peers who hold these attitudes are more likely to respond to strain such as relationship separation through lethal violence compared to other men. Similarly, proprietary and entitlement attitudes are consistently found to be related to male lethal and non-lethal partner violence (Daly \& Wilson, 1988; Dobash et al., 2007; 
Polk, 1994; Wilson \& Daly, 1993a). Men who live in societies, subcultures, or familial contexts where proprietary attitudes are more strongly endorsed would be more likely to react negatively to instances of separation or experiences of losing or not maintaining control. It is, thus, expected that men who hold proprietary and entitlement are more likely to perpetrate IPH when faced with strain compared to other men.

The effects of strain, such as partner separation, on coping strategies may further be moderated by attachment styles. Research on non-lethal partner violence suggests that violent men are more likely to display insecure attachment styles and greater partner dependency compared to non-violent men (Babcock, Jacobson, Gottman, \& Yerington, 2000; Murphy, Meyer, \& O'Leary, 1994). Dutton $(2002,2003)$ argues that fear of rejection is particularly relevant in explaining lethal and non-lethal partner violence perpetration by males, as fearful men react with rage to abandonment by their partner. Although attachment has not previously been identified by GST as a conditioning variable, theoretically, this may be an important influence. It is expected that while a secure attachment style will help buffer the effects of separation on experiences of negative emotions, insecure attachment styles (e.g., fearful) will serve to exacerbate this relationship.

In summary, drawing on the GST and partner violence literature, it is hypothesized that being prevented from (or losing) control, experiencing relationship separation or child custody disputes, receiving a protection order or suspecting infidelity are sources of strain for male perpetrators of IPH. Whether males faced with these strains use legitimate or illegal coping mechanisms depends largely on the mediating factors of negative emotional reactions and a number of moderating factors. It is hypothesized that the effect of strain on IPH will be greater for those individuals who experience intense negative emotions such as anger, rage, and jealousy. It is further hypothesized that characteristics such as negative emotionality, low constraint, insecure attachment styles, condoning partner violence or associating with peers 
who do, and holding proprietary beliefs increase the likelihood of IPH perpetration. This may help explain why the majority of controlling males (e.g., patriarchal terrorists, see Johnson, 1995) do not commit homicide. Although the process of experiencing strain and emotions are the same for women, the content differs in material ways.

\subsection{Female Perpetrators of Intimate Partner Homicide}

\subsubsection{Sources of strain}

Women who kill their partners have often been exposed to frequent and severe emotional, physical, and sexual violence, lending support for a self-defense perspective (Browne, 1987; Peterson, 1999; Walker, 1989; Wolfgang, 1957). The link between victimization and perpetration of partner violence among women has also been established in GST research (Katz, 2000). Research further suggests that men who threaten or are abusive toward children or other household members are at an increased risk of being killed by their female partner (Browne, 1987; Campbell et al., 2003; Stout, 1993). As Walker (1989, p. 138) notes, child abuse often acts as the 'catalyst' for battered women who kill their partners. In GST terminology, victimization is the presentation of negatively valued stimuli (see Agnew, 1992), and it is expected that direct exposure to abuse, or vicarious abuse directed towards children in the relationship, act as sources of strain for women. The experienced magnitude of this type of strain plays a particularly important role, as escalation in frequency and severity often precedes female-perpetrated IPH (see Browne, 1987). In addition, the threat of future violence acts as anticipated strain. As Browne (1987) notes, one of the key distinguishing factors separating women who kill from other abused women are the male partners' lethal threats.

Experiences of violence may also affect women's ability to achieve positively valued goals. Research suggests that while female role identity is grounded in conceptions of interpersonal primary relationship ties and nurturing ability, male roles are based on 
individuality and occupational status (Browne, 1987; Thoits, 1991). Broidy and Agnew (1997) note that women who are exposed to violence in intimate relationships may experience being prevented from achieving positively valued goals such as achieving and maintaining healthy romantic relationships. As strain intensity is particularly affected by its centrality (Agnew, 2001), women whose roles as partners, wives, or mothers are central and salient to their concept of self would be more affected by this source of strain than women whose interpersonal ties with their partner remains secondary to other role identities.

Furthermore, research suggests that women in abusive relationships experience restricted freedom (Browne, 1987; Peterson, 1999; Walker, 1989). Stark (2007) notes that abusive men control their partners by limiting their contact with friends and family, thus building a control barrier between the partner and the outside world. This not only prevents the abuse from being disclosed to third parties but also restricts self-expression, individuality

and personal choice. Similarly, women in abusive relationships may experience loss of identity (Mills, 1985). Identity is socially constructed, and limited contact with others makes it difficult for women to relate to themselves other than through the perceptions of their abusive partner (Stark, 2007). Mills (1985) explains how restricted freedom limits the validation by others for women in these circumstances. This process of validation is vital to the construction and preservation of identity (Mills, 1985). It is, therefore, expected that restricted freedom and loss of identity experienced by women in abusive relationships act as removal of positively valued stimuli and/or as prevention from achieving positively valued goals.

\subsubsection{Negative emotional reactions to strain}

According to GST, anger is particularly conducive to criminal involvement. However, as noted by Walker (1989), the emotions present in male IPH perpetrators, including anger and jealousy, are simply not explanatory in terms of women who kill their partner. Instead, 
the majority of these women kill out of terror. Self-help explanations of female IPH perpetration also highlight the role of fear and the use of violence as a survival mechanism (Peterson, 1999). Browne (1987) compares the experiences of women in abusive relationships to that of victims of other forms of trauma such as disaster and war, noting that fear and desperation characterizes the emotional reactions of these women. However, as noted, the emotional state most conducive to crime is expected to be anger. According to GST, fear should correlate less with outer-directed criminal behavior and more with escapist behavior, such as running away from the strain or using drugs. Perhaps women in these circumstances experience anger in conjunction with fear, with exposure to extremely severe forms of strain such as persistent domestic violence leading to outer-directed forms of violence as a means of survival. This is an issue that requires further examination, as limited research has explored these questions.

\subsubsection{Factors conditioning the effect of strain on intimate partner homicide}

Of the conditioning variables identified by GST to impact criminal involvement, access to social support and social control are particularly relevant in the case of female perpetrators of IPH. ${ }^{2}$ The buffering effects of social support on stress in general, and on mental and physical health problems among abused women especially, have long been recognized in research (see Cohen \& Wills, 1985; Coker et al., 2002). Applied to IPH, research by Dutton, Hohnecker, Halle, and Burghardt (1994) shows that women charged with attempted or actual homicide of their abusive partner experienced less perceived social support prior to the homicide than a control sample of abused women seeking mental health treatment.

\footnotetext{
${ }^{2}$ Although other conditioning variables, such as holding beliefs favorable to crime, may also be of relevance they are not discussed here due to their relative absence in the literature on female IPH perpetration. However, this should not preclude them from future theoretical and empirical examination.
} 
Availability of legitimate resources is another important factor explaining the behavior of abused women who kill their partners (Browne, 1987). Consistent with self-help arguments, female-perpetrated IPH is a form of social control that occurs in situations where the law is perceived to be unavailable or ineffective (Black, 1983; Peterson, 1999). Examining the correlation between resources and female-perpetrated homicides in the United States, Browne and Williams (1989) found that States with higher availability of legal and extra-legal resources for battered women reported lower rates of these types of homicides. In cases where resources are available, victims' prior contact with the justice system may affect their help-seeking behavior if they experience that option to be exhausted (Grant \& Curry, 1993). As conditioning variables, it is expected that the perceived availability of social support systems, including friends and relatives, and perceived access to legal resources act to buffer the effect of strain and negative emotions on criminal coping for victims of domestic violence. Conversely, perceived limited access to these types of formal and informal service restricts the amount of legal coping mechanisms available, in turn, increasing the likelihood of IPH perpetration.

In summary, it is expected that women who kill their intimate partners experience one or more of the following sources of strain preceding the homicide incident: physical and emotional victimization, vicarious victimization directed towards children, social isolation and loss of identity. It is further hypothesized that female perpetrators of IPH react to these strains with fear, terror and desperation. Moderating the effect of these strains and emotions are availability of support services and access to legal resources.

\section{Strategies for Research}

Current IPH research frequently relies on official data such as police records and sentencing information. Although informative, these sources provide only static snapshots of the incident and offer limited insight into the dynamic context of homicide perpetration. 
Other studies innovatively give voice to victim experiences through interviews with proxy (relatives and/or friends) and attempted IPH victims (e.g., Campbell et al., 2003). These studies are important in that they inform risk assessment tools and prevention strategies, although they are limited to victim perceptions of perpetrator motives and cognitions. The GST research hypotheses put forth in this article require a different approach. Research examining strain, emotions, and conditioning variables require methodological designs and data collection tools that involve direct research with IPH perpetrators, capture the genderdifferentiated nature of IPH and offer reliable measures of retrospective accounts of homicide events.

\subsection{Conducting research with IPH perpetrators}

GST is an individual-level theory focusing on perpetrator experiences of strain and negative emotions. Therefore, GST research should aim to collect data from perpetrators through interviews or other self-report measures. Although access to official data is often more practical, such an approach is limited, as subjective evaluations of events and experiences cannot be ascertained. While there is merit in understanding the objective strains that cluster together for IPH perpetrators, it is also of theoretical importance to ask individuals to identify events they find stressful and to talk about their experiences of these events (Agnew, 2001). This further extends to understanding emotions. Although getting perpetrators to talk about and recognize emotional states certainly can be challenging given that male perpetrators of partner violence may repress or misinterpret their emotions (Browne, 1987; Umberson, Anderson, Williams, \& Chen, 2003), face-to-face interviews with perpetrators will provide a more informed account of emotions experienced compared to official data and victim accounts. Similarly, conditioning variables, such as personality 
characteristics, attitudes, and cognitions, are often better measured through direct contact with perpetrators. ${ }^{3}$

\subsection{Measuring the gender-differentiated nature of IPH}

Much of current IPH research embraces gender-specific approaches. Rarely has research on homicide collected data on both men and women who kill their partners, thereby hindering gender comparisons. This methodological approach is understandable, given that theoretically the etiology of IPH has predominantly been understood through gender-specific explanations. However, GST contends that while the processes involved are similar, the types of strains, negative emotions and conditioning variables differ between men and women. Thus, homicide research informed by GST should, to the extent that it is possible, include data from both men and women in order to enable gender comparisons. Given the comparatively low rate of females who kill their partners this may prove a difficult task, particularly for large quantitative studies, perhaps necessitating the use of disproportionate stratified sampling techniques. There is also merit in exploring GST through more in-depth interviews with sub-samples of male and female IPH perpetrators. Although these types of qualitative approaches limit generalizability, they provide greater sensitivity to gender differences based on personal experiences and accounts of perpetrators. These approaches also avoid sample size specifications often required for advanced statistical analyses.

\subsection{Reliably measuring retrospective accounts}

According to GST, there should be clear causality between strain, experiences of negative emotional states, and the homicide act. Thus, the link between strain and homicide should be mediated by negative emotional states. However, the rarity of homicide events

\footnotetext{
${ }^{3}$ It is acknowledged that this kind of research is ambitious but important. Few perpetrator-based interview studies have been conducted enabling quantitative analyses of homicide. Notable exceptions are the Murder in Britain Study and the Australian Homicide Project, data from which may provide the scope to examine these propositions.
} 
necessitates the use of retrospective rather than prospective research, making it difficult to separate causality from correlation. An innovative tool which may be employed in homicide research is the life event calendar. This methodology has increasingly been used in criminological research to improve memory recall and establish timelines suitable for research on causal processes (Roberts \& Horney, 2010). This technique allows researchers to collect information on the timing and sequencing of events retrospectively, enabling examinations of intra-individual variability in strain across time and whether life events shape developmental risks and courses of offending.

\section{Conclusion}

Current theoretical explanations of IPH offer significant contributions toward understanding how male entitlement and control, lack of access to resources and support, subcultural attitudes, and situational characteristics contribute to IPH. The application of GST to IPH provides an opportunity to extend current theoretical knowledge in a number of ways. First, it provides gender sensitivity to a phenomenon previously understood as genderspecific or gender-neutral. Second, it illuminates the role of emotions, a much neglected variable in IPH research. Third, it provides an understanding of the ways in which individuals cope with experiences of strain and negative emotions and identifies moderating variables that contribute to coping mechanisms. Fourth, it provides a coherent and parsimonious model for organizing a wide range of correlates. Fifth, it provides clear testable statements to guide future research. Although GST is not the only framework with the potential to add value to the theoretical landscape of IPH, the face validity of these arguments warrants further attention.

Importantly, the merit of applying GST to IPH is not solely theoretical. Although most individuals who experience strain and negative emotions do not engage in lethal violence, from a preventative perspective it is important to understand why some individuals 
do. Should empirical analyses of the hypotheses put forth in this article be supportive of a GST application, this would give rise to a number of practical and policy implications. Although experiences of strain and negative emotions are inevitable, the ability to cope legitimately with these experiences is crucial. A GST approach provides information on how individuals deal with stress, and importantly, when comparing male and female IPH perpetrators, a greater understanding of similarities and dissimilarities in stress, emotions, and coping mechanisms can be achieved. Not only can this enhance our understanding of why men are overrepresented as perpetrators of IPH, but also why some women engage in this form of violence. Such information would help inform police organizations, domestic violence support services, child protection agencies, and social welfare services.

Nevertheless, it is important to keep in mind that applying a stress and coping perspective on partner violence does not mean that the act of killing a partner is justified or excusable; rather, it provides an explanatory foundation for advancing theoretical knowledge as well as preventative action.

It is acknowledged that IPH is a serious and impactful criminal event that has significant consequences for families and communities. At the same time, it is recognized that perpetrators of IPH may differ in their levels of intentionality under unique contexts. While some IPH events result from explicit planning and a high degree of intentionality other events occur through the risks and harms associated with non-lethal intimate partner violence.

Ultimately, a comprehensive theory of criminal offending needs to account for such heterogeneity, and it is asserted that Agnew's GST provides a comprehensive explanation of the various pathways to IPH. In this way, we think this represents a meaningful advance in the theoretical understanding of IPH. 


\section{References}

Agnew, R. (1992). Foundation for a general strain theory of crime and delinquency. Criminology, 30(1), 47-87.

Agnew, R. (2001). Building on the foundation of general strain theory: Specifying the types of strain most likely to lead to crime and delinquency. Journal of Research in Crime and Delinquency, 38(4), 319-361.

Agnew, R. (2002). Experienced, vicarious, and anticipated strain: An exploratory study on physical victimization and delinquency. Justice Quarterly, 19(4), 603-632.

Agnew, R. (2006). Pressured into crime: An overview of general strain theory. Los Angeles: Roxbury Publishing Company.

Agnew, R., Brezina, T., Wright, J. P., \& Cullen, F. T. (2002). Strain, personality traits, and delinquency: Extending general strain theory. Criminology, 40(1), 43-72.

Anderson, A. S., \& Lo, C. C. (2011). Intimate partner violence within law enforcement families. Journal of Interpersonal Violence, 26(6), 1176-1193.

Babcock, J. C., Jacobson, N. S., Gottman, J. M., \& Yerington, T. P. (2000). Attachment, emotional regulation, and the function of marital violence: Differences between secure, preoccupied, and dismissing violent and nonviolent husbands. Journal of Family Violence, 15(4), 391-409.

Black, D. (1983). Crime as social control. American Sociological Review, 48(1), 34-45.

Brezina, T. (1996). Adapting to strain: An examination of delinquent coping responses. Journal of Research in Crime and Delinquency, 34(1), 39-60.

Broidy, L., \& Agnew, R. (1997). Gender and crime: A general strain theory perspective. Journal of Research in Crime and Delinquency, 34(3), 275-306.

Browne, A. (1987). When battered women kill. New York: Free Press. 
Browne, A., \& Williams, K. R. (1989). Exploring the effect of resource availability and the likelihood of female-perpetrated homicides. Law \& Society Review, 23(1), 75-94.

Campbell, J. C., Webster, D., Koziol-McLain, J., Block, C. R., Campbell, D., Curry, M. A., Gary, F., Glass, N., McFarlane, J., Sachs, C., Sharps, P., Ulrich, Y., Wilt, S. A., Manganello, J., Xiao, X., Schollenberger, J., Frye, V., \& Laughon, K. (2003). Risk factors for femicide in abusive relationships: Results from a multisite case control study. American Journal of Public Health, 93(7), 1089-1097.

Cohen, S., \& Wills, T. A. (1985). Stress, social support, and the buffering hypothesis. Psychological Bulletin, 98(2), 310-357.

Coker, A. L., Smith, P. H., Thompson, M. P., McKeown, R. E., Bethea, L., \& Davis, K. E. (2002). Social support protects against the negative effects of partner violence on mental health. Journal of Women's Health \& Gender-Based Medicine, 11(5), 465-476.

Conger, R. D., Lorenz, F. O., Elder, G. H., Jr., Simons, R. L., \& Ge, X. (1993). Husband and wife differences in response to undesirable life events. Journal of Health and Social Behavior, 34(1), 71-88.

Daly, K., \& Chesney-Lind, M. (1988). Feminism and criminology. Justice Quarterly, 5(4), 497-538.

Daly, M., \& Wilson, M. (1988). Homicide. New York: Aldine De Gruyter.

Dearden, J., \& Jones, W. (2008). Homicide in Australia: 2006-2007 National Homicide Monitoring Program (NHMP) Annual Report. AIC Reports: Monitoring Reports. Canberra: Australian Institute of Criminology.

DeKeseredy, W. S., \& Schwartz, M. D. (1998). Male peer support and woman abuse in postsecondary school courtship: Suggestions for new directions in sociological research. In R. K. Bergen (Ed.), Issues in intimate violence (pp. 83-96). Thousand Oaks, CA: Sage Publications. 
Dobash, R. E., \& Dobash, R. P. (1979). Violence against wives: A case against the patriarchy. New York: Free Press.

Dobash, R. E., Dobash, R. P., Cavanagh, K., \& Medina-Ariza, J. (2007). Lethal and nonlethal violence against an intimate female partner: Comparing male murderers to nonlethal abusers. Violence Against Women, 13(4), 329-353.

Dugan, L., Rosenfeld, R., \& Nagin, D. S. (2003). Exposure reduction or retaliation? The effects of domestic violence resources on intimate-partner homicide. Law \& Society Review, 37(1), 169-198.

Duntley, J. D., \& Buss, D. M. (2008). The origins of homicide. In J. D. Duntley \& T. K. Shackelford (Eds.), Evolutionary forensic psychology: Darwinian foundations of crime and law (pp. 41-64). Oxford: Oxford University Press.

Dutton, D. G. (2002). The neurobiology of abandonment homicide. Aggression and Violent Behavior, 7(4), 407-421.

Dutton, D. G. (2003). The abusive personality: Violence and control in intimate relationships. New York: Guilford Press.

Dutton, M. A., Hohnecker, L. C., Halle, P. M., \& Burghardt, K. J. (1994). Traumatic responses among battered women who kill. Journal of Traumatic Stress, 7(4), 549-564.

Felson, R. B., \& Tedeschi, J. (1993). A social interactionist approach to violence: Crosscultural applications. Violence and Victims, 8(3), 295-310.

Froggio, G., \& Agnew, R. (2007). The relationship between crime and “objective” versus “subjective” strains. Journal of Criminal Justice, 35(1), 81-87.

Garcia-Moreno, C., Jansen, H. A. F. M., Ellsberg, M., Heise, L., \& Watts, C. H. (2006). Prevalence of intimate partner violence: Findings from the WHO multi-country study on women's health and domestic violence. The Lancet, 368, 1260-1269. 
Gauthier, D. K., \& Bankston, W. B. (2004). "Who kills whom" revisited: A sociological study of variation in the sex ratio of spouse killings. Homicide Studies, 8(2), 96-122.

Gondolf, E. W. (1985). Men who batter: An integrated approach for stopping wife abuse. Holmes Beach, FL: Learning Publications.

Grann, M., \& Wedin, I. (2002). Risk factors for recidivism among spousal assault and spousal homicide offenders. Psychology, Crime \& Law, 8(1), 5-23.

Grant, B., \& Curry, G. D. (1993). Women murderers and victims of abuse in a southern state. American Journal of Criminal Justice, 17(2), 73-83.

Hirschi, T. (1969). Causes of delinquency. Berkeley: University of California Press.

Holtzworth-Munroe, A., Meehan, J. C., Herron, K., Rehman, U., \& Stuart, G. L. (2000). Testing the Holtzworth-Munroe and Stuart (1994) batterer typology. Journal of Consulting and Clinical Psychology, 68(6), 1000-1019.

Johnson, C. (2005). Come with daddy: Child murder-suicide after family breakdown. Crawley: University of Western Australia Press.

Johnson, H., \& Hotton, T. (2003). Losing control: Homicide risk in estranged and intact intimate relationships. Homicide Studies, 7(1), 58-84.

Johnson, M. P. (1995). Patriarchal terrorism and common couple violence: Two forms of violence against women. Journal of Marriage and the Family, 57(2), 283-294.

Katz, R. (2000). Explaining girls' and women's crime and desistance in the context of their victimization experiences. Violence Against Women, 6(6), 633-660.

Klein, D. (1981). Violence against women: Some considerations regarding its causes and its elimination. Crime \& Delinquency, 27(1), 64-80.

Mazerolle, P., Piquero, A. R., \& Capowich, G. E. (2003). Examining the links between strain, situational and dispositional anger and crime: Further specifying and testing general strain theory. Youth and Society, 35(2), 131-157. 
McCloskey, L. A. (2001). The "Medea complex" among men: The instrumental abuse of children to injure wives. Violence and Victims, 16(1), 19-37.

Mills, T. (1985). The assault on the self: Stage in coping with battering husbands. Qualitative Sociology, 8(2), 103-123.

Moffitt, T. E., Krueger, R. F., Caspi, A., \& Fagan, J. (2000). Partner abuse and general crime: How are they the same? How are they different? Criminology, 38(1), 199-232.

Murphy, C. M., Meyer, S.-L., \& O'Leary, K. D. (1994). Dependency characteristics of partner assaultive men. Journal of Abnormal Psychology, 103(4), 729-735.

Nicolaidis, C., Curry, M. A., Ulrich, Y., Sharps, P., McFarlane, J., Campbell, D., Gary, F., Laughon, K., Glass, N., \& Campbell, J. C. (2003). Could we have known? A qualitative analysis of data from women who survived an attempted homicide by an intimate partner. Journal of General Internal Medicine, 18(10), 788-794.

Paternoster, R., Brame, R., Bachman, R., \& Sherman, L. W. (1997). Do fair procedures matter? The effect of procedural justice on spouse assault. Law \& Society Review, 31(1), 163-204.

Peterson, E. S. L. (1999). Murder as self-help: Women and intimate partner homicide. Homicide Studies, 3(1), 30-46.

Piquero, N. L., Gover, A. R., MacDonald, J. M., \& Piquero, A. R. (2005). The influence of delinquent peers on delinquency: Does gender matter? Youth \& Society, 36(3), 251-275.

Piquero, N. L., \& Sealock, M. D. (2000). Generalizing general strain theory: An examination of an offending population. Justice Quarterly, 17(3), 449-484.

Piquero, N. L., \& Sealock, M. D. (2004). Gender and general strain theory: A preliminary test of Broidy and Agnew's gender/GST hypotheses. Justice Quarterly, 21(1), 125-158.

Polk, K. (1994). When men kill: Scenarios of masculine violence. New York: Cambridge University Press. 
Roberts, J., \& Horney, J. (2010). The life event calendar method in criminological research. In A. Piquero \& D. Weisburd (Eds.), Handbook of quantitative criminology (pp. 289312). New York: Springer.

Sherman, L. W. (2003). Reasons for emotion: Reinventing justice with theories, innovations, and research: The American Society of Criminology 2002 presidential address. Criminology, 41(1), 1-38.

Stahly, G. B. (2000). Women with children in violent relationships. Journal of Aggression, Maltreatment \& Trauma, 2(2), 239-251.

Stark, E. (2007). Coercive control: How men entrap women in personal life. Oxford: Oxford University Press.

Stout, K. D. (1993). Intimate femicide: A study of men who have killed their mates. Journal of Offender Rehabilitation, 19(3/4), 81-94.

Straus, M. A. (1980). Social stress and marital violence in a national sample of American families. Annals of the New York Academy of Sciences, 347, 229-250.

Swatt, M. L., \& He, N. (2006). Exploring the difference between male and female intimate partner homicides: Revisiting the concept of situated transactions. Homicide Studies, 10(4), 279-292.

Taylor, R., \& Jasinski, J. L. (2011). Femicide and the feminist perspective. Homicide Studies, 15(4), 341-362.

Thoits, P. A. (1991). On merging identity theory and stress research. Social Psychology Quarterly, 54(2), 101-112.

Thomas, S. P. (1993). Women and anger. New York: Springer.

Tjaden, P., \& Thoennes, N. (2000). Full report of the prevalence, incidence and consequences of violence against women: Research report. Washington, DC: US Department of Justice National Institute of Justice. 
Trainor, C., \& Mihorean, K. (2001). Family violence in Canada: A statistical profile 2001. Ottawa: Canadian Centre for Justice Statistics.

Umberson, D., Anderson, K. L., Williams, K., \& Chen, M. D. (2003). Relationship dynamics, emotion state, and domestic violence: A stress and masculinities perspective. Journal of Marriage and Family, 65(1), 233-247.

Walker, L. E. (1989). Terrifying love: Why battered women kill and how society responds. New York: Harper \& Row.

Wallace, A. (1986). Homicide: The social reality. Sydney: New South Wales Bureau of Crime and Statistics.

Websdale, N. (1999). Understanding domestic homicide. Boston: Northeastern University Press.

Wilson, M., \& Daly, M. (1992). Who kills whom in spouse killings? On the exceptional sex ratio of spousal homicides in the United States. Criminology, 30(2), 189-216.

Wilson, M., \& Daly, M. (1993a). An evolutionary psychological perspective on male sexual proprietariness and violence against wives. Violence and Victims, 8(3), 271-294.

Wilson, M., \& Daly, M. (1993b). Spousal homicide risk and estrangement. Violence and Victims, 8(1), 3-16.

Wolfgang, M. E. (1957). Victim precipitated criminal homicide. Criminal Law, Criminology and Police Science, 48(1), 1-11. 